\title{
A REAPPRAISAL OF MARKETING DEFINITION AND THEORY
}

\author{
Ran Liu \\ Old Dominion University, Norfolk, VA
}

\begin{abstract}
Based on a historical literature review, this study examines the definition of marketing and different marketing theories used in academic research. After a comprehensive review of different approaches to the definition of marketing, this paper provides a unique description of marketing, highlighting the new role of marketing in value creation during the traditional transaction exchange.
\end{abstract}

Keywords: Marketing, Definition, Theory, Paradigm, Science.

DOI: http://dx.doi.org/10.15549/jeecar.v4i2.170

\section{INTRODUCTION}

Understanding marketing definition and marketing theory is the foundation to start a comprehensive marketing study. This paper attempts to review the literature of these two areas and tries to generate some new thoughts on it to align with the development of today's marketing knowledge in academia.

\section{MARKETING DEFINITION}

\section{Different Versions of Marketing Definition}

With an on-going process of change of in the pattern of business and technology, the meaning of marketing, as an essential component of business, is subject to change and is not easy to define. Bartels (1951) defines marketing as "that field of study which investigates the conditions and laws affecting the distribution of commodities and services. It is the institutionalized function of providing consumers with goods for their use" (p. 327). This definition focuses on the solely commercial goods and lacks an emphasis on exchange and social ingredients of marketing.
In 1968, in order to meet the outline of his famous general theory, Bartels redefined the definition of marketing as "the process whereby society, to supply its consumption needs, evolves distributive systems composed of participants, who, interacting under constraints -- technical (economic) and ethical (social) creates the transactions or flows which resolve market separations and result in exchange and consumption" (p. 32). Compared to his previous version, this definition focuses more on process and society, and it also indicates the importance of marketing in exchange, which is a significant improvement on the understanding the marketing concept.

The American Marketing Association (AMA) recently updated its definition of marketing to "the activity, set of institutions, and processes for creating, communicating, delivering, and exchanging offerings that have value for customers, clients, partners, and society at large" (AMA, 2013). Although this is not a perfect definition for marketing, it does give some essential elements of marketing that leads to discussions, such as scope of the marketing concept, the idea of the process, the meaning of 
exchange, consumer orientation, and social marketing.

\section{The Emergence of the Marketing Concept} and Its Normative Approaches

Borch (1964) says that the debate on the definition of the marketing concept and the value of the marketing has been ongoing since the introduction of marketing philosophy in the 1940s. Borch goes on to say that there is little debate, however, on the idea that the adaption of marketing has led business management to a new approach that is customer oriented and focuses on markets' wants and needs. However, the opinions on the benefits of marketing are varied, and some scholars have been expressing their concerns about some of the significant downsides of the marketing concept.

Kaldor (1971) states that predicting market wants and needs is easier said than done. He notes that there is always a gap between the market's needs and the firm's ability to satisfy those needs. Not only because the market may not be able to recognize its needs, but also because it is not always clear what kind of product will satisfy those needs and there is always a limitation when firms try to choose what they can do.

Some researchers believe that the profitdriven marketing concept is not ethical and it conflicts with the firms' social responsibility. Bell and Emory (1971) proposed a revised marketing concept in which consumers' satisfaction and participation in an integrated operation process, not profit, becomes the focus of marketing activities.

Bennett and Cooper (1979) even go further and state that the consumer-oriented process of the marketing concept may discourage products innovation because consumers usually suggest minor improvements rather than major changes. They advise that technological development, not market orientation, should be the key to success.

From the discussion of the emergence of the marketing concept, we found that the definition of marketing should be descriptive and less value judgmental, should focus on what the scope of marketing is instead of focusing on what it should or shouldn't to do. It is understandable that there are some negative views on the adaptation of the marketing concept in business management. While we utilize those concepts with caution, we also need to realize that when we study marketing as a science, we need to go beyond those normative descriptions, which relate to value judgments and are subject to debate, and try to approach the marketing concept from a macro and positive perspective. From this standpoint, the marketing concept will remain as one of the most significant milestones in business philosophy and will continue to add value to businesses that use marketing processes.

\section{The Discussion on the Scope of Marketing}

The scope of marketing includes broadly diversified subjects such as consumer behavior, product management, marketing communication and brand equity. Hunt (1978) introduced three dichotomies model to categorize marketing scope: profit and nonprofit sector, micro and macro, positive and normative. Micromarketing studies marketing activities at individual units' level, while macro marketing refers to the higher level of aggregation, such as marketing systems or groups of consumers. Some marketers also suggest that micromarketing emphasizes the internal interests of a firm while macro marketing focuses on the interests of external society, such as social responsibilities. Profit part of the model includes the study that aims to deal with a profit related situation, whereas nonprofit part of the model is to deal with the studies that exclude the realization of profit. Positive marketing is to describe and understand an existing marketing activity or a phenomenon, whereas normative marketing is related to value judgment and attempts to prescribe what organizations or individuals should to do in marketing systems (see Appendix). Hunt (1976) believes that in order to justify that marketing is a science, not an art, it should not be restricted to the profit-micronormative dimension. Instead, marketing should use more positive approaches to establish more scientific discoveries.

Bartels $(1951,1968)$ sees that marketing is a complimentary two-fold process: technical and social process. The technical process includes activities companies use to pursue their strategic business goals, such as product, promotion, price, institutions, flows, and processes. The social process is a higher-level concept of marketing to meet the responsibilities of emerging social interest in 
new situations, which gives marketing a new area to explore.

Some elements of the technical process are used by Neil Modern (1964) to create his famous concept of the marketing mix, which includes of elements and forces that influence marketing decision making. The most common classification of those factors is the four Ps: price, product, promotion, and place.

As a significant contribution to marketing definition, Hunt's three-dichotomy approach defines marketing with a measurable boundary, which gives more tools to categorize business phenomena by different marketing scopes using a scientific methodology.

\section{Exchange in Marketing}

Based on the AMA's definition of marketing, "exchange" is a keyword that defines marketing. The essence of marketing is the transaction which is defined as the exchange of values between different social units, the concept of exchange is the core of marketing (1972, Kotler). Baozi (1975) argues that exchange is a complex and multidimensional process that is one of the critical concerns in marketing. He categorized exchange into three forms of transactions: restricted, generalized and complex exchange. Ferrel (1977) claimed that although the definition of exchange includes both social and economic exchange, marketing should not include all human exchanges and should only include the exchange that is relevant to marketing. Otherwise, the broader definition of marketing may cause identity crisis in marketing definition. There is no doubt that exchange is one of the key elements in defining marketing. It is essential to limit the meaning of exchange so that its meaning is narrow enough to make it relevant to business.

\section{Traditional Marketing vs. Social marketing}

The AMA definition says that marketing is "exchanging offerings that have value for customers, clients, partners, and society at large" (AMA, 2013). From this definition, we know that customers and clients are not the only concern for marketers, but also the society as a whole. Traditional marketing concerns the investigation of commodities and services at firms' level (Bartels, 1951). On the contrast, social marketing considers the social impact of marketing activities at the society level.
Social marketing uses marketing skills into social action efforts to make it more effective and efficient to maximize the desired audience response and enhance social ends. At the same time, social marketing also concerns the social consequences of marketing policies and decisions (Zaltman, 1971; Lazer \& Kelly, 1973).

Since social marketing is related to value judgments, it is a normative approach to marketing activities and does not generate theory development per se, but the study and analysis aspects of social marketing using scientific methodology are very important. Compared to commercial marketing, social marketing has the potential to influence much more population and benefit the society as a whole at more significant level.

\section{The Need for a Value-centered New Marketing Definition}

From the discussions above, we conclude that the definition of marketing should reflect the descriptive marketing concept and should have a specific boundary to make it measurable, and exchange is a key element of marketing, and it should include a social marketing element. Those discussions are to be used as suggestions to develop a new definition based on the views in literature, which is marketing is the activities and value creation processes that facilitate exchanging offerings within the domain of business and benefit the society at large. One of the characteristics of the definition is that it attempts to place more emphasis on value creation through marketing function, which has not been the focus in previous definitions. At the same time, the definition also tries to give a clear boundary to make the marketing concept big enough to include social phenomena and narrow enough to measure its effectiveness by experimental scientific methods.

\section{MARKETING THEORY}

Hunt (1971) defines theory as systematically related set of testable statements that include law-like generalizations specifying variable relationships. By definition, a theory must meet four basic criteria: conceptual statements, scope limitations, relationship specification, and testability. There are many diverse theories in marketing history; some of them became cornerstones of today's marketing study and the 
paper lists some of them below.

\section{Marketing is an Art vs. Marketing is a Science}

\section{Marketing is an Art}

Vaile (1949) states that because any theoretical development in marketing comes primarily as a result from other disciplines, such as economics and psychology, marketing will remain an art, not a science. Hutchinson (1952) holds a similarly negative opinion about marketing as a science and argues that marketing cannot be a science because it depends on other sciences, it is slow to develop a unique system of theory body, and marketing practitioners are not scientists.

\section{Marketing is a Science}

On the other hand, other scholars believe that marketing is a science. Converse (1945) is the first one to write a journal article stating that marketing can be developed as science if it utilizes scientific research methods. Buzzell (1963) states that marketing has the potential to be a science if it meets the four criteria of science: 1) has classified and systematized of knowledge; 2) that knowledge is organized around central theories or general principles; 3 ) usually expressed in quantitative terms; 4) permits prediction and control of events. Bartels (1951) defines science as a branch of systematized knowledge with a distinct field of investigation or object of study. He concludes that marketing must be a science because it uses scientific tools, such as experimentations to explain scientific discoveries. Bartels sees the study of marketing as combined with other disciplines such as economics, and its analysis is more descriptive rather than theoretical, but he believes this is normal in the early stages of a scientific study.

Hunt (1976) provides positive and normative dichotomy approaches to categorize analysis as descriptive or prescriptive. Hunt states that positive marketing tries to describe, explain and predict marketing activities while normative marketing attempts to prescribe what a marketing organization or individual should do. He sees a science usually employ positive approaches to explain and predict phenomena and that marketing should not be restricted to the micro/normative dimension, which can jeopardize the characteristic of marketing as a science.

\section{The Scientific approach to explain marketing phenomena}

According to Nagel (1961), there are four types of scientific explanations. This part of the paper is trying to explain how those types of explanations are tied to marketing phenomena.

\section{The deductive model.}

Nagel (1961) defined the deductive model as a type of explanation in which a deductive argument is formed to explain marketing phenomena and the explicandum is a "logically necessary consequence of the explanatory premises" (p. 21). The explanation and the premises need to be true or follow either lawlike assumptions or experimental laws. For example, when we try to answer why an issue with product safety undercuts consumers' brand loyalty, we assume the existence of a strong connection between brand loyalty and product safety. The explanatory premise, in this case, is common sense that has been statistically demonstrated by historical marketing phenomena, leading scholars to assume that the premises can be generalized by a statistical law. However, since the implicit premise of a connection between brand loyalty and product safety is not fully formulated, we assume that we can make explicit on the premises so that the explanation shows a deductive pattern.

\section{Probabilistic explanations}

In this case, a statistical assumption is used to explain or support marketing phenomena (Nagel, 1961). For instance, in the question, "Does advertising investment have a strong impact on the performance of a firm?" a relationship between advertising investment and financial performance is used as a precondition for the explanation. For the phenomenon that we try to explain, we do not have any general laws, as are available in physics, to use as an explanatory tool. An acceptable way to explain this unique marketing phenomenon is to compare multiple firms' advertising investments and their financial performances, so we can establish not only a significant relationship between the two variables but also a causal relationship to explain that a certain percentage of changes in financial performance is due to a certain 
percentage of change in advertising investment.

\section{Functional or teleological explanations}

Functional or teleological explanations focus on a unit's function in maintaining the operation of a system that unit belongs to. One of the criticisms of functionalism is that it does not give any evaluation of the conditions under which the operation of the unit can function well (Negal, 1961). In marketing, as an example, the question of "why does a firm have a marketing department?" would be an issue of a company's organizational structure or the function of marketing as a unit of the company. A functional explanation focuses on the function of marketing in such a way that marketing is the only way to differentiate a firm's products/services, so the firm gains a competitive advantage by adding more value to its products/services. This type of explanation describes the function of the marketing department as a critical operation for the maintenance of firms' business activities. Although the explanation does not mention the guidelines under which the marketing activities can differentiate its products/services well, it does explain how the marketing department contributes to the company to make its existence relevant.

\section{Genetic explanations}

As one type of explanation that may or may not be distinctive, Genetic explanation describes how a previous system has been transformed into a later or current one (Nagel, 1961). As an example, "why does online marketing play such an important role in business today?" In order to explain the complex phenomena of today's online marketing reality, we have to check the historical facts in the marketing arena to compare the major marketing activities in different historical periods. A comparative analysis reveals that technology, especially the Internet, plays an essential role in today's marketing functions that is distinctive compared to earlier stages of marketing operations. When using theories to predict the transformation of marketing, it is important to understand that transformation in the context of sequential changes including developing technology.

From multiple perspectives, there is no doubt that marketing is a social science that interrelated with other disciplines. As marketing studies are using scientific methodology, such as normative experiment and quantitative explanation to describe and predict social phenomena, it meets every requirement of being a scientific discipline. Nagel's four types of scientific explanation models illustrate that marketing is a science and can be approached scientifically. Prior researchers have studied these approaches based on their range and scope of marketing activities, with middle range and general theory representing the major standpoints.

\section{Middle Range Theory Vs. General Theory General theory}

Bartels believes that marketing studies have been using scientific methods and there is a universal theory that can explain all marketing phenomena. To be a general theory, it must be monolithic representing integration from one's knowledge base and must also be multipartite representing an integration of series of subtheories (1968).

Hunt (1971) does not agree with the approach of Bartels' general theory. He argues that for marketing to be a science, general laws or broad principles must be established; predictions based on development of laws should be of social import; theory and hypothesis should be used to extend knowledge and guide managerial means; both abstraction and concrete facts should be used to interpret marketing phenomena. Most importantly, Hunt insists that the systematically related set of statements, including law-like generalization and empirical testability should be the criteria to judge if it can be considered as a theory. Hunt does not see how the seven sub-theories, the components of Bartels's general theory, meet those three criteria.

\section{Middle Range Theory}

Middle range theory proposed by Merton (1968) tries to bridge the gap between the empirical evidence and the broad general theory. Merton argues that instead of trying to explain the whole world, we need to focus on the measurable pieces of reality so that we get valuable marketing applications from study. Bourgeois (1979) further classifies middle range theory to substantive theory and formal theory. He sees substantive theory as centered on data 
analysis, while formal theory is generated through the comparative analysis of various substantive theories. He states that because of the feature of predictability, the development of well-framed theory that explains the relationship of marketing phenomena is possible.

Middle range theory is accepted by the majority of marketing scholars because it is relatively easy to implement and more likely to yield general applications that are invaluable to business reality. As an example, if it is based on the middle range theory, we can state that, although people make their decisions for different reasons, group behaviors have a uniformity that is predictable using valid and reliable measures.

\section{THE EMERGING NEEDS FOR A NEW MARKETING THEORY AND DEFINITION}

With those fundamentals of basic marketing theory having been discussed from the middle range perspective, the paper examines the relevance of marketing in today's business reality by determining the importance of value creation from marketing in transaction exchange. Prahalad and Ramaswamy (2004) state that value can either be created by the firm and then transferred to customers or co-created by the firm and the consumers. Marketing plays a critical role in both situations. As the paper stated before, marketing is a science that focuses on value creation processes that facilitate exchanges. The emphasis on valuecreation differentiates this approach from many others. Marketing has been used as a tool to facilitate exchange, but in reality its impact is far greater. The value generated by marketing to meet consumers' needs, firms' organizational goals, and society's well being has been underestimated. Therefore, it is crucial for marketing academics to identify, measure and predict the processes by which marketing maximizes value-creation during exchanges. By doing so, a new paradigm focused on valuecreation emerges to contribute to the ongoing theory development in the science of marketing.

\section{REFERENCES}

America Marketing Association (AMA). Definition of marketing, 2013, www.ama.org/AboutAMA/Pages/Definitionof-Marketing.aspx. Accessed Oct. 15, 2016

Bartels, R. (1951). Can marketing be a science? Journal of Marketing.15(3), 319-328.

Bartels, R. (1968). The general theory of marketing. The Journal of Marketing. 29-33.

Bennett, R. C., \& Cooper, R. G. (1979). Beyond the marketing concept. Business Horizons, 22(3), 76-83

Bourgeois, L. J. (1979). Toward a method of middle-range theorizing. Academy of Management Review, 4(3), 443-447.

Buzzell, R. I., \& Wilsie, C. P. (1963). Genetic investigations of brown keel tip color in Lotus corniculatus L. Crop Science, 3(2), 128130.

Converse, P. D. (1945). The development of the science of marketing: An exploratory survey. Journal of Marketing, 10(1), 14-23.

Hunt, S. D. (1976). The nature and scope of marketing. Journal of Marketing, 40(3), 1728.

Hunt, S. D. (1978). A general paradigm of marketing: in support of the'3-dichotomies model'. The Journal of Marketing, 107-110.

Kaldor, A. G. (1971). Imbricative marketing. The Journal of Marketing, 19-25.

Merton, R. K. (1968). Social Theory and Social Structure: Enl. Ed. Free Press.

Nagel, E. (1961). The structure of science: Problems in the logic of scientific explanation.

Prahalad, C.K. and Venkat Ramaswamy (2004), The Future of Competition: Co-creating unique value with customers. Boston: Harvard Business School Press.

\section{ABOUT THE AUTHOR}

Ran Liu, email: rliu001@odu.edu

Mr. Ran Liu, is a marketing scholar whose research interests include word of mouth (WOM), branding, and social media. He works as a researcher and instructor at old Dominion University in Norfolk, Virginia. 


\section{APPENDIX}

The Three Dichotomies of Model of Marketing

Positive
Profit sector
Micro
1. Problems, issues, theories, and research concerning:
a. Individual consumer buyer behavior
b. How firms determine prices
c. How firms determine products
d. How firms determine promotion
e. How firms determine channels of distribution
f. Case studies of marketing practices

Macro

3. Problems, issues, theories, and research concerning

a. Aggregate consumption patterns

b. The institutional approach to marketing

c. The commodity approach to marketing

d. The functional approach to marketing

e. Legal aspects of marketing

f. Comparative marketing

g. The efficiency of marketing systems

h. Whether marketing spurs or retards economic development

i. Power and conflict relationships in channels of distribution

j. Whether the marketing concept is consistent with consumers' interests
Normative

2. Problems, issues, normative models, and research concerning how firms should:

a. Determine the marketing mix

b. Make pricing decisions

c. Make product decisions

d. Make promotion decisions

e. Make packaging decisions

f. Make purchasing decisions

g. Make international marketing decisions

h. Organize their marketing departments

i. Control their marketing efforts

j. Plan their marketing strategy

k. Develop and manage relationships with stakeholders

I. Manage retail establishments

m. Manage wholesale establishments

n. Implement the marketing concept

o. Be market-oriented

p. Manage brand equity

4. Problems, issues, normative models, and research concerning:

a. How marketing can be made more efficient

b. Whether distribution costs too much

c. Whether advertising is socially desirable

d. Whether consumer sovereignty is desirable

e. Whether stimulating demand is desirable

f. What kinds of laws regulating marketing are optima

g. Whether vertical marketing systems are socially desirable

h. Whether marketing should have special social responsibilities

\section{Nonprofit sector}

Micro

5. Problems, issues, theories, and research concerning:

a. Consumers' purchasing of public goods

b. How nonprofit organizations determine prices

c. How nonprofit organizations determine products

d. How nonprofit organizations determine promotion

e. How nonprofit organizations determine channels of distribution

f. Case studies of public goods marketing

Macro

7. Problems, issues, theories, and research concerning:

a. The institutional framework for public goods

b. Whether television advertising influences elections

c. Whether public service advertising influences behavior (e.g., Smokey the Bear)

d. Whether existing distribution systems for public goods are efficient

e. How public goods are recycled

6. Problems, issues, normative models, and research concerning how nonprofit organizations should:

a. Determine the marketing mix (social marketing)

b. Make pricing decisions

c. Make product decisions

d. Make promotion decisions

e. Make packaging decisions

f. Make purchasing decisions

g. Make international marketing decisions (e.g., CARE)

h. Organize their marketing efforts

i. Control their marketing efforts

j. Plan their marketing strategy

k. Develop and manage relationships with stakeholders

8. Problems, issues, normative models, and research concerning:

a. Whether society should allow politicians to be "sold" like toothpaste

b. Whether the demand for public goods should be stimulated

c. Whether "low informational content" political advertising is socially desirable (e.g., ten-second "spot" commercials)

d. Whether political advertising should be held to the same standards as commercial advertising

Resource: Hunt, S. D. (2010). Marketing Theory: Foundations. Controversy, Strategy, Resource-Advantage Theory, ME Sharpe, Armonk, NY., P. 12-1. 
